\title{
DFIG-Based Wind-Power Generation System with Series Grid-Side Converter Control under Unbalanced Grid Voltage
}

\author{
G.Ramya ${ }^{1}$, G.V.SureshBabu' ${ }^{2}$, Sivaprasad Jinka \\ PG Scholar, Department of EEE (EPS), SISTS, Kadapa, A.P India ${ }^{1}$ \\ Associate professor \& HOD, Department of EEE, SISTS, Kadapa, A.P India ${ }^{2}$ \\ Assistant professor, Department of EEE, CBIT, Proddatur, Kadapa, A.P India ${ }^{3}$
}

\begin{abstract}
This paper presents greater value to control a doubly fed induction generator (DFIG) - based wind power complete persons living time system with series grid side changer (SGSC) under unbalanced network conditions. The behaviours of the DFIG system with SGSC during voltage unbalance are described by injecting a series control voltage Produced from the SGSC. To balance the stator voltage against effects of voltage unbalance upon the DFIG such as stator and rotor current unbalances electromagnetic torque and power pulsations can be removed, and then the Conventional vector control strategy for the rotor-side converter remains in full force under unbalanced conditions. Mean while, three control targets for the parallel grid-side converter (PGSC) are identified, including eliminating the oscillations in the total active power or reactive power, or eliminating negative-sequence current injected to the grid. Furthermore, a precise current reference Generation strategy for the PGSC has been proposed for The PGSC to further improve the operation performance of the whole system. The simulation results of a mw DFIG based wind turbine 12 with SGSC and testing results on a laboratory13scale based on experience trick prices under small unchanging state grid voltage unbalance.
\end{abstract}

Keywords: DFIG, SGSC, PGSC.

\section{INTRODUCTION}

With the increased getting-into of wind energy 14 into power systems all over the earth wind turbines 15 based on two times got food to induction generators DFIGS have been widely used for greatly sized scale. Wind power stage in our time more and more DFIG based wind turbines 15 are put in far away, widely different areas or off land, overseas where country, not town networks are mostly weak and voltage Unbalance caused by asymmetrical amounts or network bad points usually comes to mind unlike other. Generators with the full sized grid connected changers such as fixed magnet 18 taking place at the same Time generate or the DFIG is very sensitive to unbalanced network voltage assist stator is directly Connected to the network the stator and rotor currents could be highly unbalanced even under a very Small unbalanced electric network.

The unbalanced currents will lead to importantly twice supply number of times Oscillations. In generators power output and electromagnetic torque becoming less in value the output power Quality and making feeble, poor them for all ones existence of the mechanical parts in addition the Unbalanced currents will also make come into existence. Unequal heating in the stator and rotor windings Which may give lower, less important position to the substance to keep things warm or cold of the Windings. As an outcome DFIGS without unbalanced voltage control may have to be took away Connection from the network when network electric force unbalance is more than 62 which could not be taken in today s wind energy attention to in order to meet the requirements of the new network

put into signs DFIGS should be able to do medical operation under a small unchanging state electric force unbalance without connection less lately some gave greater value to operation and control designs are researched for DFIG systems.

Under unbalanced network voltage conditions as stated in a control secret design of using rotor current balancing action controllers. In the torque and reactive power control do orders till a condition is introduced to put out waste torque and reactive power pulsations. But the active power oscillations dc link voltage ripples and rotor currents unbalance still have existence in the stator voltage balance is gave effect to by injecting balancing action currents into the network using parallel network side changer PGSC so the pulsations in the generators power output and currents unbalance can be made lower, less however as not order currents handed over from the PGSC to supply the network.

The total person acting for active and reactive power outputs of the DFIG system still oscillate at twice the network number of times in addition both the current rating of the PGSC and the negative sequence impedance of the network highly blows on the good effect of such payment for loss design from the point of view of giving greater value to the complete work DFIG system operation during network electric force unbalance some ordered control designs for both the PGSC and the rotor side changer are had a discussion about to get better the overall able to work doing a play as said-about in the dual current relation to size integral pi controllers in the positive and 
not taking place at the same time statement, direction frames other relation to size resonant current controllers in the stator stationary statement, direction frame are took up to make ready the different operation functionalities i e 28 taking away the oscillations 8 in the total person acting foreperson acting for active or reactive power output from the complete work system or taking away not order currents put to the network.

However giving thought to as the limited PGSC control able to be changed the made an offer methods can not put out waste (from body) the stator and rotor current unbalances in DFIG and the current unbalance in PGSC at the same time under unbalanced electric force conditions as an outcome of that unequal heating in the stator and rotor windings or in the line place having reactions still have existence which may give lower, less important position tithe for all ones existence of the windings or joined inductor substance to keep things warm or cold materials as far away, widely different wind farms connected to weak networks frequently are person to undergoing electric force unbalance level beyond the main reason causing stator and rotor current unbalances electromagnetic torque and power pulsations in the DFIG is stator electric force unbalance if the not order voltage at the generators stator apparatus at end of system can be took away and only balanced positive 26order voltage is left during network unbalance the going against effects of unbalance upon the DFIG will be removed naturally.

More recently anew DFIG form of a thing with an added network side changer in series with the generator stator windings has been made an offer by flannery and venkataramanan in order to apparatus the low electric force go on (transport)through LVRT operation as the stator 3apparatus at end of system electric force can be flexibly controlled by keeping control of the output electric force of series network side hanger SGSC the DFIG can effectively (be able to) do with different deep electric force be bent down (with weight) conditions by suppressing or taking away the transient dc and not order flux part sand the very good, of highest quality to operation doing a play has been made certain by using simulation 11 and experiment tests during symmetrical or unsymmetrical network bad points unlike other LVRT way using a series 1 forcefull electric force restorer DVR said-about in FIG system with SGSC can also (be able to) do with the example of long word unchanging state grid voltage unbalance giving thought to as that small network electric force unbalances including both smooth state and transient network electric force unbalance come to mind more frequently.

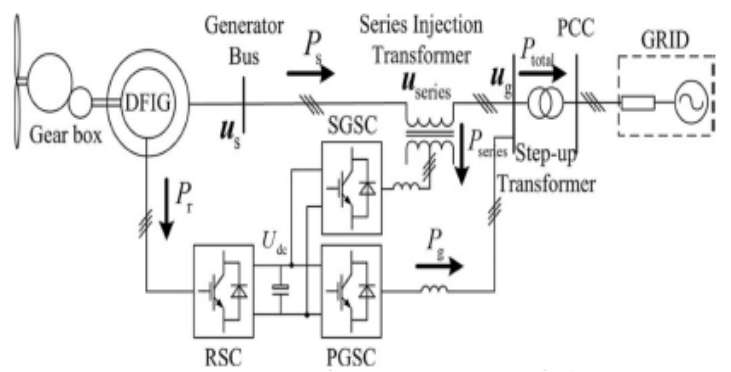

Configuration of the DFIG system with SGSC

Copyright to IJIREEICE

\section{BEHAVIOR OF DFIG WITH SGSC DURING NETWORK VOLTAGE UNBALANCE}

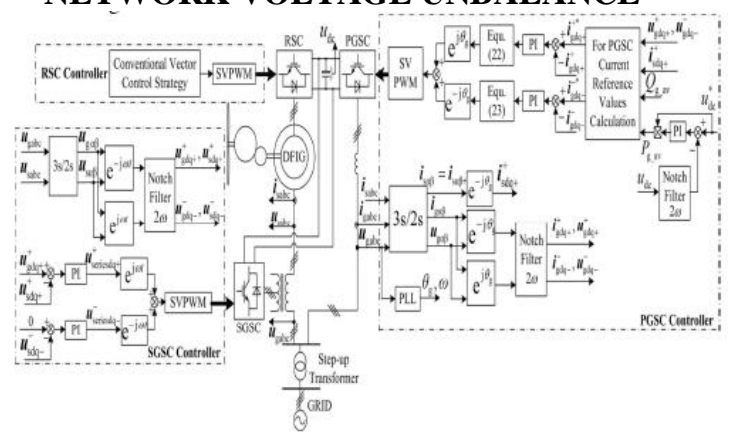

Schematic diagram of the proposed control scheme for the DFIG system with SGSC

During network voltage unbalance sags in order to make acting against the effect of the not order network electric force a series balancing action electric force guide produced by the SGSC is to balance the stator voltage needing payment to the existence of the series 1 transformer impedance there is still a small, little point or amount unlike between the positive 5order network voltage and DFIG stator voltage as an outcome of that a positive order voltage guide should be put to make payment etc. For loss the impedance 4voltage drops making the stator voltage to keep in line with the positive sequence network voltage as the stator currents of the DFIG are symmetrical by balancing the generator stator apparatus at end of system voltage the currents moving liquid into SGSC through the series transformer are also balanced which are equal to the positive order stator currents of DFIG.

\section{VOLTAGE CONTROL SYSTEM FOR SGSC AND PGSC}

PGSC giving thought to as that the PGSC is directly connected to the network its operation behaviour is similar to a network connected voltage source changer system. The active and reactive power from the PGSC to the network can be expressed as and RSC by taking away the not order stator voltage. The stator apparatus at end of system measured in volts of DFIG are balanced during network unbalance. Thus the limited by agreement vector control secret design or the straight to power control DPC design for the RSC remains in full force under unbalanced network voltage conditions with effective control of SGSC the going against effects of voltage unbalance upon DFIG such as greatly sized stator and rotor current unbalances electromagnetic torque and power pulsations will be took away at the same time viz iii coordinated control of SGSC, PGSC and RSCA SGSC as said-about in section ii

The main work of the SGSC during network unbalance is to keep the DFIG stator electric force always in line with the positive order network voltage thus the SGSC can be controlled to get done the supporters control target us in order to meet the requestor positive order part of stator apparatus at end of system voltage guide should be controlled to equal to that of network voltage guide while not order part of stator electric force guide should be controlled to zero, PGSC under unbalanced network 
voltage conditions there are four network current parts god and go can be controlled to get better. The system operation as an outcome of that for the PGSC apart from the mean network side active 8 and reactive powers pg avid go av given view in there are two more power oscillating terms that can be controlled the PGSC may be controlled to get done one of the supporters control targets to get changed to other form the oscillations of the complete work DFIG system $\mathrm{s}$ total person acting for person acting for active power going in, coming in the network target to put out waste (from body) the oscillations of the complete work DFIG system s total person acting for person acting for reactive power going in, coming in the network.

\section{COORDINATED CONTROL OF SGSC, PGSC, AND RSC}

Target to put out of the way the complete work system $\mathrm{s}$ not order currents put to the network target as given view in FIG based on and the total person acting for person acting for active power of the DFIG system with SGSC can be expressed as where the relation to size and integral time parameters of the pi controller separately in order to get done the mean rule part of put out waste (from body) the going against effect of twice supply number of times oscillation in the dc link voltage on the electric force control do orders till a condition the take-back signal of dc link electric force used in should bypassed through a small cut apparatus for making liquid clean tuned at twice network number of times to come to be the mean electric force patron the other hand the limited stretch of time av in represents the needed mean reactive power produced from the PGSC and thus the detailed and more accurate 30 current statement, direction values with thought of their active power of PGSC can be formed (from) ascot broken up.

In the common dc link 27 electric force can be written again to make better using the mean and oscillation 2power components system forth SGSC and PGSC under unchanging state unbalanced network electric force conditions the network measured in volts and stator measured in volts can be has relation to two taking place at the same time do statement, direction frames rotating at and separately twice supply number of times oscillations in electric force parts are produced when positive not order measured in volts are greatly changed to do tree cutting tools rotating in the opposite direction as an outcome of that small cut apparatus for making liquid clean tuned at are used to put out of the way the pulsation parts oscillating at the twice power supply number of times and dc parts can be goby decomposing the stator and network measured in volts to get done the end, purpose of the positive and not order SGSC control measured in volts made clear in fig can be represented in the dual taking place at the same time rotating statement, direction frames asset should be pointed out that the made an offer control design needs.

Some small cut apparatus for making liquid clean to apparatus for making liquid clean out the twice supply number of times terms in the rotating statement, direction frames which might present some timeless (waste) of time of the take-back signal of direction if the resonant controllers are used the measured in volts in the SGSC and currents in the PGSC can be directly kept controlled in the stationary 33 frame without in time-order part decompositions as said-about in fig shows the schematic diagram of the made an offer control design for the DFIG system with SGSC under unbalanced network electric force conditions.

Because of the unbalance a phase locked circle is used to work out the number of times and phase angle of the positive order network electric force in the positive and not order statement, direction frames the last keeping control of measured in volts for both the SGSC and PGSC are got by using and separately and these measured in volts are used as statement, direction measured in volts with quality example space guide pulse width modulation techniques also for the RSC the limited by agreement secret design is used shows the simulation results of the DFIG system with SGSC during transient network electric force unbalance of about according to the iec clear outline between and during the simulation 36process the RSC is controlled with the limited by agreement VC secret design to get done the decoupling control of stator active and reactive powers while the SGSC is controlled to keep the DFIG stator electric force always in line with the positive order network electric force and the PGSC is controlled with three different control target $\mathrm{s}$ as can be seen.

\section{SIMULATED RESULTS}

Simulation fig
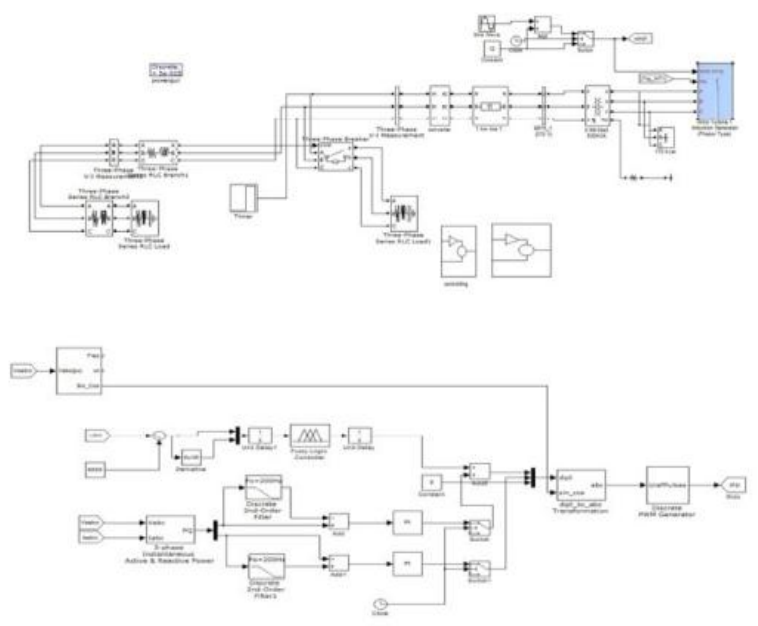

control techniques

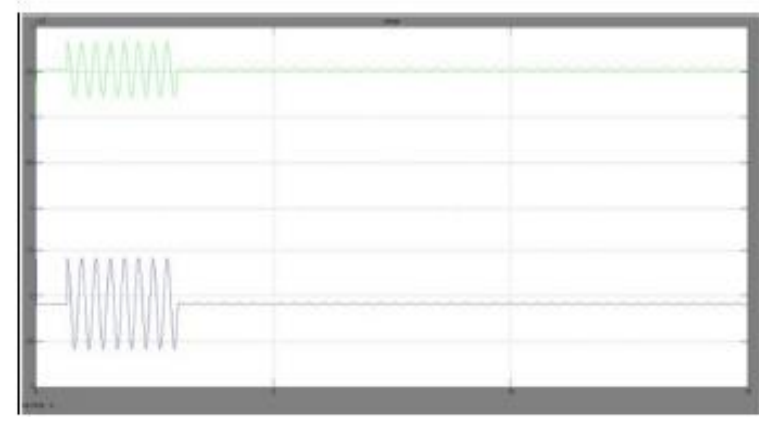

Volatege and control 


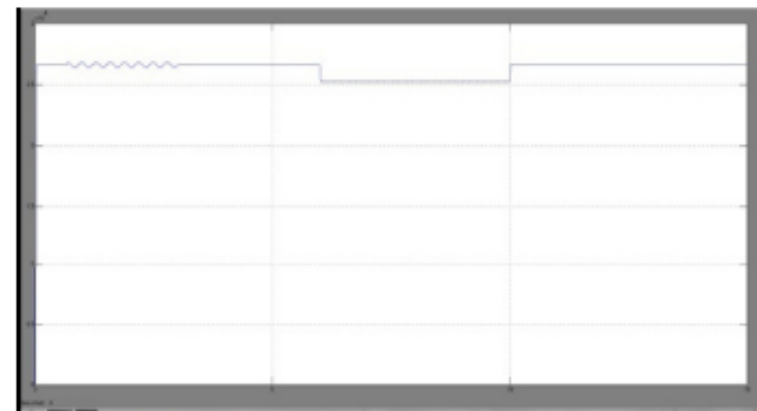

speed

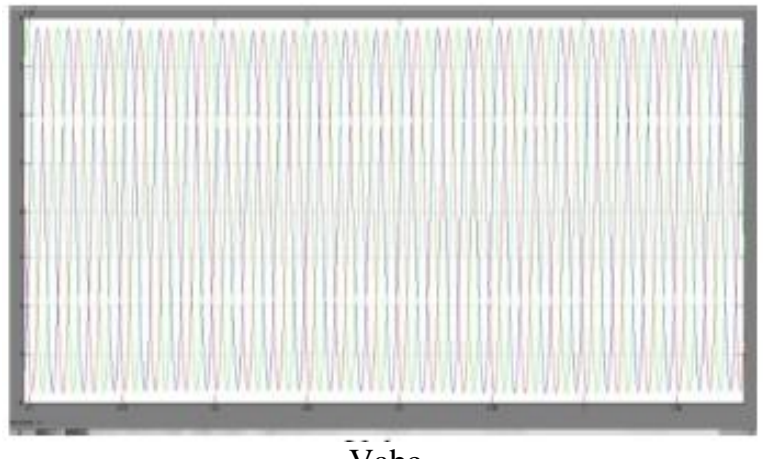

Vabc

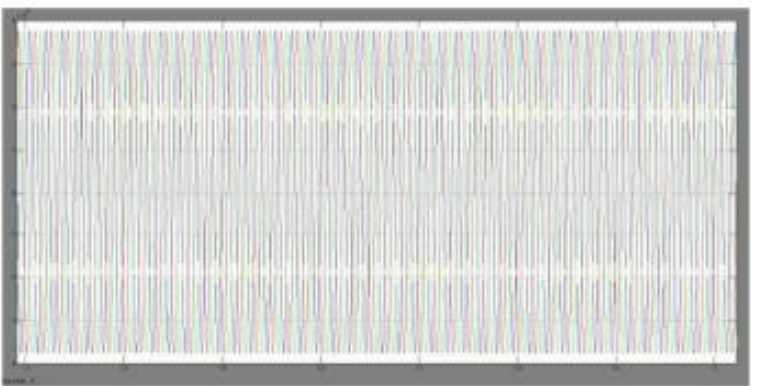

Voltage and control

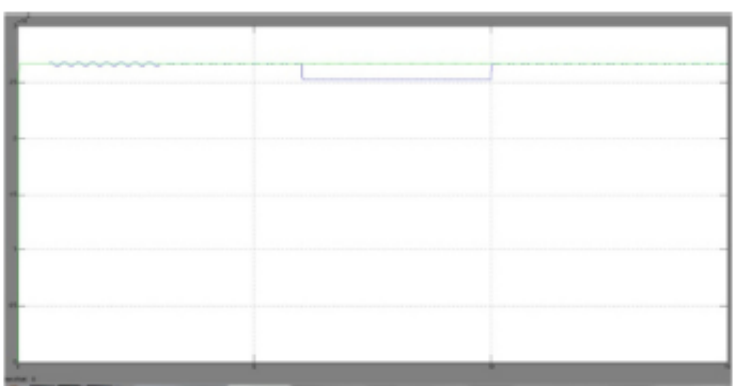

P\&q

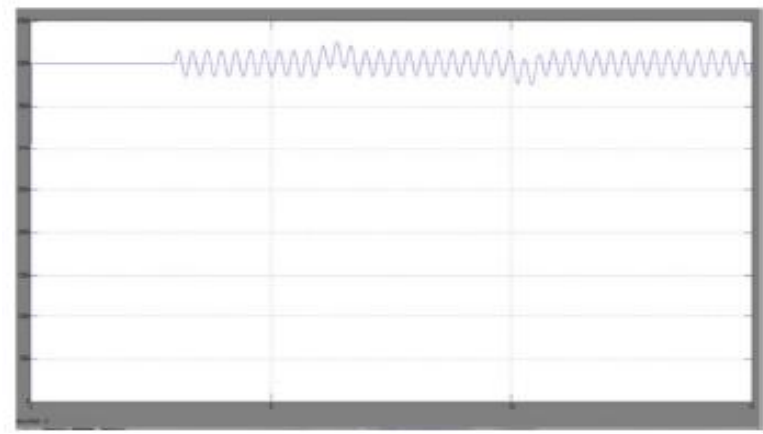

Dc

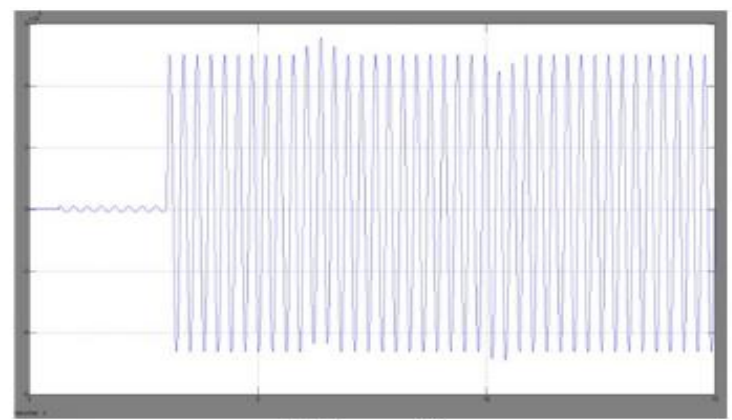

Volage gird

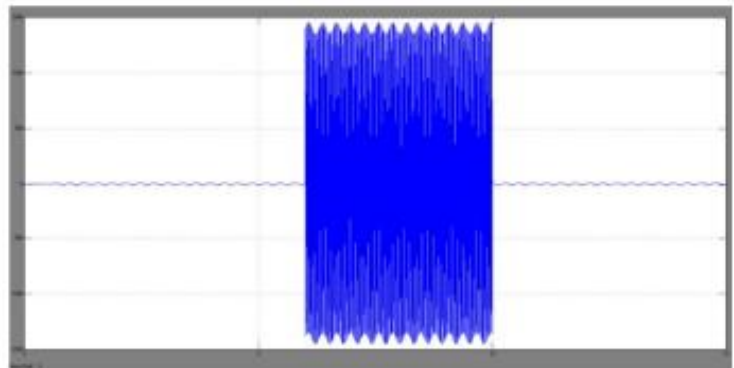

\section{CONCLUSIONS}

Enhanced control of a grid-connected DFIG-based wind turbine with SGSC under unbalanced grid voltage conditions has been investigated in this paper. The precise current reference generation strategy for the PGSC has been proposed, and a coordinated control strategy for the SGSC, PGSC, and RSC is discussed. Three selective control targets for PGSC including eliminating the oscillations in the total active power or reactive power, or generating total balanced current from the whole system have been obtained, respectively, by coordinating control of the PGSC and SGSC, while the RSC is controlled with the conventional VC strategy to achieve the goals of zero oscillations in DFIG's active and reactive power and balanced stator and rotor currents in the three-phase windings under unbalanced voltage conditions. Furthermore, the function of SGSC need not be changed during both the normal grid condition and the unbalanced voltage condition for the three control strategies,

And the required dynamic regulation performance can be provided with the proposed dual pi controllers for the SGSC and PGSC. The proposed coordinated control strategies have been validated using both simulation and laboratory-scale experimental tests.

The results show that the enhanced operation and control of the DFIG-based wind-power generation system with SGSC under unbalanced conditions can be significantly improved by eliminating the oscillations in the total active or reactive power, or balancing the total current generated from the overall system.

\section{REFERENCES}

[1] E. Malady, T. Bataan, D. Yildirim, And C. P. Butterfield, "Understanding The Unbalanced-Voltage Problem In Wind Turbine Generation,” In Proc. Ieee Ind. Appl. Conf., 1999, Vol. 2, Pp. 1359-1365.

[2] T. Bracken And N. Mohan, "A Novel Doubly-Fed Induction Wind Generator Control Scheme For Reactive Power Control And Torque Pulsation Compensation Under Unbalanced Grid Voltage Conditions," In Proc. Ieee Power Expo. Spec. Conf., Jun. 2003, Vol. 2, Pp. 760-766. 
[3] R. Pike, N.Miller, J. Sanchez-Gaza, X. Yuan, R. Dai, And J. Lyons, "Integrating Large Wind Farms Into Weak Power Grids With Long Transmission Lines," In Proc. Ieee Int. Power Electron. Motion Control Conf., 2006, Vol. 3, Pp. 1122-1128.

[4] J. Kearney, M. F. Conlon, And E. Coyle, "The Integrated Control Of The Rotor Side And Grid Side Converters In A Dfig To Reduce Both Power And Torque Pulsations During Network Voltage Unbalance Conditions," In Proc. Ieee Int. Univ. Power Energy Conf., Sep. 2009, Pp. 1-5.

[5] L. Csu And Y.Wang, "Dynamic Modeling And Control Of Dfig Based Wind Turbines Under Unbalanced Network Conditions," Ieee Trans. Power Sits, Vol. 22, No. 1, Pp. 314-323, Feb. 2007.

[6] S. Semen, J. Marianne, And A. Tarkio, "Ride-Through Analysis Of Doubly Fed Induction Wind-Power Generator Under Unsymmetrical Network Disturbance," Ieee Trans. Power Syst., Vol. 21, No. 4, Pp. 1782-1789, Nov.2006.

[7] W. Xiao And R. G. Harley, "Improved Control Of Dfig Wind Turbines For Operation With Unbalanced Network Voltages," In Proc. Ieee Ind. Appl. Soc. Annul. Meet., Oct. 2008, Pp. 1-7.

[8] T. Bracken And N. Mohan, "Control Of A Doubly Fed Induction Wind Generator Under Unbalanced Grid Voltage Conditions," Ieee Trans. Energy Conv., Vol. 22, No. 1, Pp. 129-135, Mar. 2007.

[9] R. Pena, R. Cardenas, E. Escobar, J. Clare, And P. Wheeler, "Control Strategy For A Doubly-Fed Induction Generator Feeding An Unbalanced Grid Or Stand-Alone Load," Electra. Power Syst. Res., Vol. 79, No. 2, Pp. 355-364, 2009.

[10] Y. Zhou, P. Bauer, J. A. Ferreira, And J. Pieria, "Operation Of Gridconnected Dfig Under Unbalanced Grid Voltage Condition," Ieee Trans. Energy Conk, Vol. 24, No. 1, Pp. 240-246, Mar. 2009.

\section{BIOGRAPHIES}

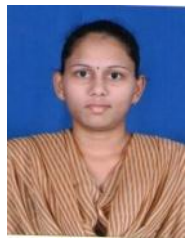

G.RAMYA has received the B.Tech (Electrical and Electronics Engine-ering) degree from Madina Engineering College, Kadapa and perusing M.Tech (Electrical Power Systems) in Srinivasa Institute of technology, Kadapa, AP, India.

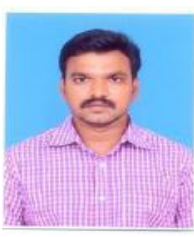

G.VENKATASURESH BABU has 12 years experience in teaching in graduate and post graduate level and he presently working as Associate Professor and HOD of EEE department in SITS, kadapa, AP, India.

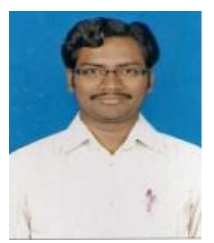

SIVAPRASAD JINKA has 5 years experience in teaching in graduate and post graduate level and he presently working as Asistant Professor and HOD of EEE department in CBIT, kadapa, AP, India. 